SEÇÃO TEMÁTICA:

CAPITALISMO, ESTADO E EDUCAÇ̃̃O:

OS LIMITES DO CAPITAL

\title{
Mais a Temer do que Esperar: educação radical e classe trabalhadora
}

\author{
Deirdre O'Neill' \\ 'University of Hertfordshire, Hertfordshire - Reino Unido
}

RESUMO - Mais a Temer do que Esperar: educação radical e classe trabalhadora. Este artigo se debruça sobre a questão de uma educação política radical a partir da perspectiva de uma classe trabalhadora global. Ele explora que forma tal educação tomaria e por que ela é fundamental para a criação de uma nova sociedade. Situando a discussão a partir de um arcabouço teórico marxista, argumenta-se que, embora seja possível a educação promover mudanças sociais, uma educação política radical só pode ocorrer fora das instituições formais de educação. O artigo explora as formas pelas quais o neoliberalismo, com o apoio da classe média, dificulta cada vez mais a educação pela busca da justiça e da libertação da classe trabalhadora. Não são oferecidas respostas definitivas, mas a possibilidade de um engajamento crítico com as questões abordadas.

Palavras-chave: Classe Trabalhadora. Global. Educação. Radical. Neoliberalismo.

ABSTRACT - Little to Hope and Much to Fear: radical education and the working class. This article engages with the question of a radical political education from the perspective of a global working class. It explores what form such an education would take and why such an education is central to the creation of a new society. Situating the discussion within a Marxist framework it argues that while it is possible for education to bring about social change a radical political education can only take place outside of the institutions of formal education. It explores the ways in which neoliberalism with the support of the middle class makes an education in the pursuit of justice and the liberation of the working class increasingly difficult. It does not provide any definitive answers but rather offers the possibility of a critical engagement with the questions it raises.

Keywords: Working Class. Global. Education. Radical. Neoliberalism.

Educação \& Realidade, Porto Alegre, v. 46, n. 3, e117080, 2021 
Mais a Temer do que Esperar

[...] a burguesia tem muito mais o que temer do que esperar da educação da classe trabalhadora (Friedrich Engels, 2005, p. 139)

Já passou o dia de tentar remendar o sistema capitalista, ele precisa ser derrubado (James Connolly, 1910).

\section{Introdução}

O objetivo deste artigo é considerar como funcionaria uma educação política radical a serviço da classe trabalhadora, que forma poderia assumir e por que sua implementação se tornou crucialmente necessária. Isso implica orientar a maneira como pensamos sobre a educação, tanto teoricamente quanto na prática, em direção a uma posição que coloque as questões de classe no centro da discussão e que veja a classe como uma relação estrutural cujas influências são tanto subjetivas quanto parte de um sistema mais amplo de condições econômicas objetivas. Implica considerar essa subjetividade e essas condições econômicas objetivas como existindo em uma relação dialética que pressupõe as formas pelas quais o poder, os recursos e as agências se organizam para impedir que a classe trabalhadora tenha acesso a elas. Implica ver a classe trabalhadora empiricamente como pessoas que dividem específicas experiências de dominação e exploração e que são apanhadas por dificuldades econômicas que limitam suas oportunidades e restringem suas chances na vida, enquanto são constantemente julgadas por aqueles que ocupam posições mais altas dentro das hierarquias de classe (Biressi; Nunn, 2013, p. 63; Mclaughlin, 2021).

Partir dessa compreensão de classe como objetiva e experiencial, entendê-la em seu funcionamento dentro dos domínios do econômico e do cultural, é considerar com seriedade as maneiras pelas quais "[...] a relação entre a cultura e a economia está cada vez mais interconectada [...] dado o movimento crescente das corporações transnacionais para monopolizar o espaço cultural" (Herschmann apud Albornoz, 2015, p. 13) e como "[...] a ideologia neoliberal tem exercido o raciocínio de mercado sobre todas as práticas e como colonizou a vida cotidiana da modernidade tardia" (Mcguigan, 2010, p. 8). Ver também: (Winlow, 2021; Fisher, 2012). Uma intervenção, como este artigo sobre a questão de uma educação política radical a serviço da classe trabalhadora, é uma tentativa de ampliar a forma como entendemos o propósito ao qual a educação serve, tanto cultural quanto economicamente, e de construir uma compreensão do potencial subversivo da educação para agir como um instrumento de mudança social (Lovett; Clarke; Kilmurray, 1983). Isso significa ver a educação como um processo cultural, não dentro da estrutura liberal em que está atualmente situada e onde reafirma as limitações que já existem, mas por meio da ótica de um objetivo explicitamente declarado de elaboração de uma visão alternativa do mundo que uma educação política radical pode alcançar. Para que tenha êxito, esta abordagem contra-hegemônica, em seu compromisso com a autodeterminação da classe trabalhadora, aceita a distinção de Marx entre 
pertencer a uma classe e a capacidade de reconhecer e agir de acordo com esse pertencimento. Essa é a principal crise que enfrentamos hoje em relação a qualquer projeto potencialmente transformador.

É importante ressaltar que este ensaio não se preocupa com as perspectivas de uma educação política radical em nenhum país específico. Embora tenha como foco a educação no Reino Unido, como um estudo de caso, muito de minha análise, no que se refere ao potencial transformador da educação em relação à classe trabalhadora, pode ser aplicado globalmente. Tampouco desejo discutir métodos de ensino e técnicas pedagógicas como se a educação fosse um processo desinteressado de comunicação e aquisição de conhecimento. Falar de técnicas e métodos dentro do sistema existente não mudará esse sistema, pelo contrário:

O sistema capitalista buscará destruir qualquer forma de pedagogia que tente educar os alunos sobre sua real situação de crise, criar uma consciência de si mesmos como força de trabalho futura e para sustentar essa consciência com uma visão crítica que busque minar o funcionamento estável da produção social da força de trabalho (Hill, 2008, p. 38).

A razão disso é que nossa compreensão da educação no presente está dentro de um sistema socioeconômico que incentiva e recompensa a implacável competição de livre mercado e o acúmulo de riqueza. A educação, dentro das instituições formais do neoliberalismo, tem pouca relevância ou benefício material para a classe trabalhadora e, em seu âmago, preocupa-se em comunicar maneiras de se adaptar à lógica do capitalismo. É por meio dessa relação recíproca entre neoliberalismo e educação que podemos abordar a questão acerca do propósito exato ao qual a educação serve.

Este ensaio é uma tentativa de formular uma resposta àquela pergunta. Mas também é uma tentativa de colocar em foco a interdependência da classe trabalhadora global e esboçar as ferramentas necessárias eficazes para desenvolver uma teoria da educação para uma classe trabalhadora global. Uma educação que pode ser colocada em prática e que crucialmente não funcione como espaço de reprodução ideológica dos senhores de um neoliberalismo que continua destruindo a vida de tantas pessoas. É uma tentativa de vincular a interdependência da classe trabalhadora, e sua relação com a educação, às questões mais amplas de emprego, economia, cultura, meio ambiente, esfera pública e às lutas políticas mais amplas da classe trabalhadora.

\section{Educação Neoliberal}

A construção de um modelo de educação que funcione como uma ferramenta potencial para o desenvolvimento de uma posição contrahegemônica capaz de desafiar o status quo deve se preocupar em abordar a política da educação no sentido macro de como construímos as 
condições para uma educação política radical, mas também no nível micro de compreensão da forma como o preconceito de classe está embutido na concepção e na oferta da educação formal (Reay, 2001, p. 23; Hill, 2018, p. 43; Friedman; Laurison, 2019, p. 57). O preconceito de classe ocorre em todos os níveis de educação; ele garante que a classe trabalhadora receba não uma educação adequada ao seu propósito, mas uma educação com o propósito de situá-la dentro do sistema de estratificação hierárquica, sobre o qual o neoliberalismo é construído e por meio do qual aqueles com poder e riqueza utilizam a educação como forma de transmissão desse poder e riqueza.

A principal maneira pela qual as famílias privilegiadas transmitem suas vantagens aos filhos é garantindo, por quaisquer meios, que seus filhos obtenham melhores qualificações educacionais do que seus pares. Para ter certeza de que existem todos os tipos de outros recursos que os favorecidos podem utilizar, mas os mais importantes parecem ser aqueles que podem ser mobilizados para melhorar o desempenho educacional das crianças (Savage, 2000, p. 90).

Precisamos revisar nossa compreensão do que constitui a educação em relação à classe trabalhadora em nosso momento atual, com um currículo conservador e restrito, testes padronizados, metas e aumento no número de privatizações dominadas pelo mercado, e a forma como esses elementos são construídos, precisamente, para reprovar a classe trabalhadora (Reay, 2017, p. 177-178; Hill, 2008, p. 41) e, no processo, reproduzir uma força de trabalho que é fácil de gerenciar e controlar (Tyler, 2013, p. 114). A crescente invasão do setor privado aos espaços educacionais serve para reforçar a relação entre educação, corporações globais, economia e classe, nas quais o desempenho educacional e o sucesso são medidos em termos estatísticos abstratos, por meio da ótica de tabelas internacionais e estatísticas da OCDE (Biesta, 2006, p. 106). A educação tornou-se mais uma mercadoria no mercado neoliberal. Marx se refere à mercantilização como um processo pelo qual “[...] uma relação social definida entre os homens [...] assume [...] a forma fantástica da relação entre as coisas". A mercantilização da educação esconde como a relação entre educação e conhecimento foi rompida e como a educação é considerada apenas em relação ao seu valor de troca. Ela não está preocupada com a capacidade de se envolver criticamente com o mundo ao nosso redor (Winlow, 2021), ela visa a capacidade de produzir passividade e gerar lucro para o capitalista que detém as forças da educação.

O sistema escolar público não funciona apenas para reproduzir as vantagens da classe média sobre a classe trabalhadora. Ele tem um propósito mais fundamental, que é ajudar a reproduzir as condições de existência da sociedade capitalista como um todo. Neste contexto, a principal função da escola é produzir o tipo de futuros trabalhadores de que a economia precisa (Hatcher, 1998, p. 15). 
O colapso pós-fordista do marxismo, no entrincheiramento do liberalismo autoritário atual e oferecendo apenas uma versão extremamente restrita da política progressista, testemunhou a rejeição da política de classe e a redução da educação a um produto de mercado desprovido de engajamento crítico e dependente de sua validade de apresentação ao mercado. Crianças caóticas da classe trabalhadora são disciplinadas em escolas que drenam dinheiro da educação das autoridades locais (Reay, 2017, p. 46-49) e milhares de crianças da classe trabalhadora são reprovadas no sistema escolar e o deixam sem nem mesmo o básico de alfabetização e matemática, junto com uma profunda desconfiança das instituições educacionais (O’Neill, 2018, p. 39). Em alguns países, às crianças da classe trabalhadora é negado até mesmo o básico fornecido pelos sistemas em vigor no norte global. Ao mesmo tempo, as universidades se encarregam de criar cursos que garantam habilidades transferíveis que serão úteis no local de trabalho, enquanto os professores acadêmicos se afogam no preenchimento burocrático de formulários e na análise de dados.

Tanto o ensino quanto a aprendizagem são voltados para a empregabilidade, confirmando a afirmação de Badious de que esta é “[...] uma situação brutal [...] em que toda a existência é avaliada apenas em termos de dinheiro" (citado por Fisher, 2012, p. 9). A abordagem neoliberal da educação resultou em um sistema educacional que está alinhado aos imperativos das metas de lucro e mercantilização sancionadas pelo Estado e que se encontra restringido pela lógica da expertise e da aquisição de capital cultural. É importante aqui considerar as implicações políticas da expressão capital cultural (Bourdieu, 1996), as formas pelas quais esse tipo de capital é crucial para a classe média e como ele garante que os membros da classe trabalhadora que passam pelo processo de escolarização, apesar das muitas barreiras colocadas em seu caminho, ainda sejam privados do acesso aos empregos que envolvem tomada de decisão por possuírem o tipo errado de capital cultural. É por meio da ótica do capital cultural que acessamos uma compreensão da maneira pela qual, em vez de pertencer a esferas mutuamente exclusivas, o poder cultural está intimamente ligado ao poder econômico e político. Como argumenta Michael Parenti (2006), “[...] não se pode falar de forma inteligente sobre cultura se, em algum ponto, também não se introduzir a dinâmica da economia política e do poder social” (p. 17). As vantagens que se acumulam devido ao fácil acesso ao que é considerado cultura legítima e valiosa desempenham uma função organizacional, que trabalha para articular e justificar os arranjos sociais das sociedades de classe estratificadas que, por sua vez, criam narrativas de inclusão e exclusão. A cultura, como Bourdieu a compreendia, não é alheia à economia ou à política; pelo contrário, está intrincadamente emaranhada com ambas em uma vedada roda de hamsters de habilidades, valores e competências que geram privilégios para os ricos e o fracasso educacional para a classe trabalhadora. O político, o social e o cultural, como um conjunto de relações, estão profundamente imbricados no sistema capitalista. Embora historicamente os marxistas tenham analisado a so- 
Mais a Temer do que Esperar

ciedade pelas lentes da economia, é importante reconhecer que a reprodução das relações de classe não depende apenas do econômico. Temos que considerar como o fator econômico afeta essas outras dimensões e a maneira como cada uma se relaciona com as outras (Fraser; Jaeggi, 2018, p. 13). Para ter sucesso, a reprodução das relações de classe requer outras agências além da econômica. "Para que se tenha uma imagem da sociedade como um todo, é necessário examinar tanto o objetivo quanto o subjetivo, que estão em jogo em qualquer período particular" (Ashman, 1998, p. 152). Como afirma o próprio Marx em uma passagem famosa: "Os homens fazem sua própria história, mas não a fazem como querem; não a fazem sob circunstâncias de sua escolha, e sim sob aquelas com que se defrontam diretamente, legadas e transmitidas pelo passado" (Marx, 1977, p. 15).

A colonização de todas as áreas da vida pessoal e cívica pela lógica do capitalismo, em suas premissas de consumismo, individualismo e competição, subverteu qualquer potencial para o desenvolvimento da educação como um processo libertador e democrático relevante para a vida contemporânea da classe trabalhadora. Uma prática de educação que se alinhe à classe trabalhadora e produza uma compreensão crítica do sistema capitalista e de como ele "[...] permeia e molda todos os aspectos da vida social" (Hatcher, 1998, p. 20) e em que a aprendizagem seja direito dos cidadãos que considerem legítimo seu processo de contestação dos pressupostos básicos das instituições que detêm o poder político.

O processo de escolarização na maioria das sociedades ignora não apenas as lutas da classe trabalhadora, mas também o conhecimento de mundo que acompanha o fato de ser classe trabalhadora. Ações industriais, greves e protestos são ignorados como componentes essenciais da educação, tanto na teoria quanto na prática. E a atividade coletiva, a cooperação e a solidariedade não são valorizadas acima do beco sem saída do individualismo (Lovett et al. 1983, p. 5). A exclusão das perspectivas da classe trabalhadora é, como Peter Stead apontou, uma forma de censura que "[...] restringe a expressão de toda uma gama de experiências” (Stead, 2001, p. 52).

Esta censura resulta na reprodução de posições ideológicas que encorajam formas de (não) ver, enquanto perpetuam as relações hierárquicas existentes cuja função é preparar as crianças para desempenharem sua função no emprego (Bowles; Gintis, 2011, p. 12) ou, como é cada vez mais o caso, no desemprego. Para o êxito desse sistema de censura, é importante que o sistema neoliberal seja apresentado como um arranjo natural e de senso comum e a possibilidade de alternativas mais justas e mais equitativas seja obscurecida. Ao mesmo tempo, em um truque ideológico que sugere uma pluralidade de opiniões, os progressistas têm permissão para questionar o sistema neoliberal e oferecer discordâncias superficiais. É claro que isso só pode acontecer dentro dos limites estabelecidos pelo próprio sistema, dentro de uma estrutura que ignora as questões de classe, mas oferece a fachada de reveses progressistas. Um exemplo disso pode ser observado nas investigações periódicas so- 
bre o motivo pelo qual o sistema educacional está reprovando as crianças da classe trabalhadora. Esses pontos de resistência muitas vezes falham em perceber quão facilmente o neoliberalismo pode assimilar a resistência com o interesse de demonstrar pluralidade (O'Neill, 2018, p. 7). Como aponta Schwartz (2015) sobre o ensino superior nos Estados Unidos: “[...] os alunos sabem por que as salas de reuniões dos conselhos corporativos devem ser mais diversificadas, mas poucos questionam o próprio conceito de governo corporativo" (p. 184).

Isso é possível porque o conceito de educação que nos é apresentado é estritamente imaginado, impingido e restrito por um ambiente institucional que valida as hierarquias sociais já enraizadas na ordem social existente e que, por sua vez, são replicadas em todos os âmbitos de outras instituições. O que fica claro, portanto, é que devemos abordar o conceito de educação em seu sentido mais amplo em relação ao papel que ela desempenha na economia política e no ambiente cultural e vê-la não simplesmente como participação das crianças em uma sala de aula, em um ambiente institucional ou como alunos nas salas de aula da universidade neoliberal. Devemos ver a educação em seu formato atual como um processo de reprodução ideológica que tem um efeito debilitante sobre o potencial de qualquer tipo de resistência política. Portanto, temos que considerar a educação como uma estratégia de controle posta em prática para ignorar, censurar ou ocultar a história e as memórias das vidas na classe trabalhadora e das lutas da classe trabalhadora, proporcionando um modo institucionalizado de educação dependente da elisão do conhecimento da classe trabalhadora e da supressão de qualquer potencial radical. Um sistema educacional mercantilizado que vê o conhecimento como uma mercadoria impelida pelas necessidades do mercado de trabalho é, por sua própria natureza, oposto a qualquer ideia de que a educação deva ser um projeto emancipatório baseado em ações para melhorar o mundo.

Isso significa que devemos estar atentos às formas herdadas e habituais de pensar sobre a educação. Precisamos reconhecer como nossa própria educação influenciou os modos de pensamento por meio dos quais entendemos o mundo. De forma decisiva, precisamos conscientemente gravitar nossa compreensão da política e das relações de poder em torno de uma perspectiva de classe materialista. Mara SaponShevin (2011), em uma referência ao sistema educacional nos Estados Unidos que pode ser aplicada de forma mais geral, aponta para o quão facilmente nossas suposições habituais podem nos levar a avaliações superficiais do propósito da educação. Ao chamar nossa atenção para essa questão, ela nos oferece a oportunidade de realinhar as formas de consciência que nossa própria educação fomentou, especialmente no que diz respeito à maneira como concebemos o sucesso e o fracasso nos sistemas educacionais. A relação entre esses dois conceitos e a maneira como são representados nas discussões convencionais da educação fortalece a reprodução geracional contínua das posições de classe. Ao invés de um alinhamento com os liberais, cujo perpétuo e angustiante debate sobre como a classe trabalhadora é reprovada pelo sistema 
Mais a Temer do que Esperar

educacional é utilizado como uma rota de fuga ideológica, devemos nos aprofundar e considerar como o sistema educacional tem sido realmente eficiente para a classe dominante. Podemos ver mais claramente a lógica do sistema se julgarmos seu sucesso ou fracasso com base na compreensão de sua necessidade de reproduzir as diferenças de classe e de preparação de certos membros da sociedade para aceitar uma posição de subserviência e trabalho manual que é distribuída negativamente por todo o âmbito de recompensas do mercado:

\begin{abstract}
Se estamos preocupados porque fracassamos em educar todas as crianças, ou porque fracassamos em preparar nossos futuros cidadãos, ou porque fracassamos no comprometimento com a equidade e a justiça social, então, sim, o sistema está fracassando. Se quisermos ver a reprodução do atual iníquo sistema, então o sistema sob o qual todos vivemos está, na verdade, funcionando perfeitamente. Ele faz um excelente trabalho ao separar os vencedores dos perdedores, perpetuando uma sociedade de classes rigorosa e criando a força de trabalho que nossa sociedade capitalista estratificada requer (Sapon-Shevin, 2011, p. 22).
\end{abstract}

Somente uma análise que tenha como central a questão de classe é capaz de enxergar o tipo de educação que a classe trabalhadora recebe em termos da reprodução bem-sucedida das hierarquias e desigualdades que estruturam as sociedades em que vivemos. Só então poderemos começar a ver a educação como uma prática estratégica conscientemente estruturada, que existe dentro de uma estrutura hegemônica projetada precisamente para reproduzir as relações de classe existentes. Esse é um sistema educacional moldado pelas demandas de um sistema capitalista que exige que as crianças da classe trabalhadora aprendam passivamente e absorvam migalhas prescritas e mercantilizadas de conhecimento, que possam ser transferidas para o mercado para serem vendidas como habilidades inadequadamente remuneradas. O sistema de educação institucional oferecido pela maioria dos países em todo o mundo não oferece nenhum movimento para que a classe trabalhadora saia de sua posição proscrita. Se ela se desloca desse lugar proscrito, esse movimento tem como premissa a assimilação do próprio status quo que a oprimiu inicialmente e que exige uma cegueira cognitiva e perceptual dos modos como as estruturas de poder operam. Essa cegueira para a maneira como as estruturas operam é um componente essencial da educação neoliberal. É o conhecimento sobre essas estruturas e a oposição consciente a essas estruturas que têm o poder de mudar a maneira como operam.

Portanto, qualquer educação política radical preocupada com a relação entre classe e educação no momento presente deve colocar como sua principal reivindicação a ideia de que uma educação política radical deve necessariamente ocorrer fora das instituições e práticas avaliativas da escolarização formal. Isso ocorre porque a educação formal, mesmo quando exemplar, não é uma educação no sentido am- 
plo da palavra, mas uma pedagogia do neoliberalismo, o que significa que a primeira premissa de uma educação política radical é a rejeição consciente da educação formal. Seria difícil argumentar que o processo de escolarização formal prepare a classe trabalhadora para desempenhar um papel ativo na sociedade ou que crie uma demanda para que a sociedade atue no interesse dos pobres e marginalizados. Ele perpetua, dentro da estrutura da meritocracia (Todd, 2021; Reay, 2017, p. 122), uma noção neoliberal do que interpreta como sucesso. O conceito de meritocracia na educação é útil como um método para defletir a atenção da desigualdade, pobreza, falta de moradia e colocar o ônus sobre o indivíduo (ou sobre a escola ou sobre os pais), projetando o sucesso educacional como um produto de trabalho árduo e comprometimento e não a partir das vantagens obtidas pela distribuição injusta do capital econômico e cultural ou das barreiras estruturais que impedem a classe trabalhadora de ter sucesso nesse sistema.

A meritocracia tem a capacidade de obscurecer as questões de classe ao mesmo tempo em que incorpora aqueles mais marginalizados dentro da estrutura neoliberal, na crença de que o trabalho árduo significará que eles terão sucesso pelo mérito. Ao mesmo tempo, fracassa em remover as estruturas que originalmente sustentam o conceito de meritocracia e funcionam como disfarce de um sistema educacional baseado na exclusão da classe trabalhadora de qualquer chance de sucesso.

\section{Classe e Classes}

Antes de entrar na discussão sobre possíveis configurações de uma educação política radical a serviço da classe trabalhadora, gostaria de apresentar o conceito de classe adotado. A discussão de uma educação radical pela e para a classe trabalhadora neste momento histórico particular depende da adoção de uma compreensão marxista de classe para a concepção teórica e prática de uma educação radical a partir da classe social. É de conhecimento geral que a transição de um modo de produção capitalista industrial para um pós-industrial, iniciada na década de 1970, desencadeou uma reformulação do ambiente socioeconômico existente. Isso desencadeou uma situação em que o conceito de classe é considerado redundante e representante de um método antiquado de explicar as relações sociais (Allman, 2001, p. 67; Biressi; Nunn, 2013, p. 171). Obviamente, essa não é uma posição lógica a se tomar. É verdade que a forma como entendemos a classe trabalhadora mudou e foi reformulada ao longo dos últimos quarenta anos ou mais. Também é verdade que a própria natureza do trabalho se transformou durante este período, especialmente nas economias ocidentais avançadas, onde os empregos mudaram da produção industrial para os setores de informações, serviços e finanças. Com as transformações nas características tradicionais dos empregos da classe trabalhadora, também houve uma mudança no engajamento da classe trabalhadora na política organizada. A filiação sindical caiu drasticamente no Reino Unido, e os alinhamentos da classe com os partidos políticos tradicionais da classe 
trabalhadora mudaram, enquanto a esfera política passou a ser dominada pela classe média (Savage, 2000, p. 154). Assim, embora não haja dúvida de que o neoliberalismo recalibrou drasticamente a classe trabalhadora, classe é uma categoria dinâmica que se ajusta às mudanças no conteúdo e na organização da produção. O que não muda é a relação da classe trabalhadora com essas forças de produção (Choonara, 2018, p. 19).

Portanto, seria um erro acreditar que essa recalibração da classe trabalhadora pode ser interpretada como a classe perdendo qualquer significado teórico ou prático. Pelo contrário, o neoliberalismo é um projeto de classe. O que significa que classe, como uma estrutura analítica a partir da qual se atribui sentido ao mundo, é tão significativa hoje quanto sempre foi: "Mascarado por uma abundante retórica sobre a liberdade individual (freedom), liberdade (liberty), responsabilidade pessoal e as virtudes da privatização, o livre-mercado e o livre-comércio, ele (o neoliberalismo) legitimou políticas draconianas destinadas a restaurar e consolidar o poder da classe capitalista” (Harvey, 2005, p. 10).

A classe trabalhadora é comumente concebida a partir da estrutura teórica do Estado-nação, mesmo quando reconhecemos a natureza global do capitalismo. Situá-la transnacionalmente e concebê-la na ótica de uma polaridade crescente entre uma classe trabalhadora global e os ricos de todos os Estados-nação sustenta a afirmação fundamental de Marx de que economicamente o capitalismo pode ser considerado como produtor de duas classes opostas: o proletariado e a burguesia. Esta afirmação tem como premissa o reconhecimento de que a experiência específica da exploração de classe em uma escala global é um resultado direto da relação da classe trabalhadora com a classe capitalista. A utilidade dessa divisão binária é que ela situa ambas as classes nas relações de produção, permitindo-nos examiná-las dialeticamente e considerar como se relacionam entre si. De acordo com Marx, é essa relação dialética que alcança o coração do capitalismo e provoca luta e conflito dentro do sistema. É essa relação antagônica, essa experiência de luta e conflito contínuo que é compartilhada pela classe trabalhadora global (Marx; Engels, 1967, p. 95).

Portanto, essa distinção aparentemente grosseira serve a um propósito analiticamente adequado se considerarmos a classe trabalhadora em termos globais. Os pobres nos países em desenvolvimento trabalham nas fábricas e campos das grandes corporações a fim de fornecer os produtos baratos exigidos pelo primeiro mundo e, ao mesmo tempo, gerar lucros enormes para essas corporações:

A experiência de pessoas em todo o mundo, que vivem e trabalham em condições semelhantes àquelas da GrãBretanha do início da era industrial, reproduz em um grau surpreendente a dos trabalhadores de Manchester, Londres ou Leeds de 150 anos atrás. Obviamente, existem diferenças. As pessoas vivem em outros climas e culturas; eles são os herdeiros de outras religiões e etnias. Apesar disso, os moradores das favelas de São Paulo, Manila ou 
Dhaka sofrem da mesma carência e insegurança que eram características de nossos próprios trabalhadores. As pessoas são pobres sempre da mesma maneira. Fome, escassez e doença não sabem nada sobre diferenças culturais, mas atormentam o corpo de hindus, animistas, nigerianos e birmaneses de maneira idêntica (Seabrook, 1999).

Portanto, embora seja necessário reconhecer e levar em consideração as diferenças e experiências locais, é crucial reconhecer e destacar até que ponto as experiências das comunidades da classe trabalhadora, independentemente de sua localização geográfica, se tornaram mais homogêneas em relação à distribuição de poder e recursos sob o ataque global da ordem neoliberal.

Não há necessidade de reprimir as diferenças dentro da classe trabalhadora ou essencializá-las. Podemos reconhecer que existam diferenças nas comunidades da classe trabalhadora de diferentes Estados-nação em relação a histórias, línguas e culturas, e podemos chamar a atenção para o fato de que grupos específicos - mulheres, crianças, pessoas de diferentes etnias etc. - enfrentam formas únicas de opressão. Ao mesmo tempo, podemos também argumentar que diante do capital global essas diferenças são subsumidas na totalidade das relações capitalistas e se vinculam no que equivale a uma confiança coletiva no mercado para atender a todas as necessidades materiais, sociais e educacionais. Também podemos argumentar que a existência de uma classe trabalhadora global cria as condições materiais para a solidariedade internacional e para a subjetividade da classe trabalhadora global, como Harvey (2005) apontou (p. 23):

O neoliberalismo, na verdade, varreu o mundo como um maremoto de reformas institucionais e ajustes discursivos. Embora muitas evidências mostrem seu desenvolvimento geográfico desigual, nenhum lugar pode reivindicar imunidade total (com exceção de alguns Estados, como a Coréia do Norte). Além disso, as regras de engajamento agora estabelecidas pela OMC (que rege o comércio internacional) e pelo FMI estabelecidas por meio da OMC (que rege o comércio internacional) exemplificam o neoliberalismo como um conjunto global de regras.

Como discutido acima, a globalização do capital destacou não as diferenças, mas as semelhanças da classe trabalhadora de diferentes nações geográficas e criou uma classe trabalhadora global. $\mathrm{O}$ compromisso com uma educação política radical em busca de justiça social e política desencadeia a força dessa classe trabalhadora global para desenvolver uma resistência à sua posição dentro do modo de produção. Como Thoburn (2007, p. 57) argumenta, as rápidas mudanças no capitalismo poderiam ser vistas como forma de fortalecimento das afinidades de classe. A classe não é apenas uma posição de dominação entre tantas outras posições de dominação, situada dentro da noção de diferenciais de poder, ela é a posição de dominação definitiva. O con- 
Mais a Temer do que Esperar

ceito de educação radical será eficaz se estiver vinculado às condições da classe trabalhadora de todas as nações e se a ação por um sistema universal ético e justo estiver situada em nossa compreensão do que constitui a educação e o papel que ela atualmente desempenha na manutenção e reprodução das relações de poder injustas. As ligações entre os projetos de educação radical em outros países tornaram-se possíveis porque as novas tecnologias nos permitem estar interconectados como nunca antes.

Em nossa discussão sobre classe também é necessário levar em consideração a classe média, uma classe cuja expansão Marx não imaginou/previu. Como David Harvey argumenta, as mudanças econômicas que abriram o caminho para o neoliberalismo não dependem apenas das elites, mas precisam também da cooperação das classes médias (Harvey, 2005, p. 12). São as classes médias que determinam a dinâmica dialética do capitalismo contemporâneo. Presos às demandas patológicas, conflitantes e contraditórias do capitalismo, os profissionais e administradores desta classe desejam o burguês (pelo que eles possuem) e temem o proletariado (por seu potencial). Essa dicotomia não é tão simples quanto parece à primeira vista. Ser classe média é "[...] internalizar o sistema de significado dominante da sociedade capitalista com sua forte ênfase no individualismo competitivo" (Benson, 1978, p. 109). São os valores da classe média empresarial que dominam em uma sociedade capitalista. Motivada pelos detentores dos meios de produção, a crença da classe média em um paradigma de realização pessoal e mobilidade individual justifica a ênfase em uma educação que nega as desigualdades que produz e o papel vital que desempenha na reprodução do sistema de classes (Lockwood, 1989; Reay, 2001).

Isso é particularmente verdadeiro no Reino Unido, onde a classe como sistema está profundamente enraizada na estrutura de sua sociedade e onde é teoricamente produtivo e politicamente conveniente levar em consideração a expansão da classe média profissional nos últimos cem anos. A cooperação a que Harvey se refere foi construída sobre um enfraquecimento contínuo da política de classe e de seu potencial para construir um imperativo politicamente transformador dedicado à luta contra a opressão estrutural. Em seu lugar, está a passagem para uma política construída sobre a rejeição do pensamento iluminista e da política de solidariedade, construída sobre a base de crenças e valores compartilhados. Isso foi substituído por uma preocupação com “[...] uma subjetividade exagerada, políticas de identidade, teorias antiempíricas de poder e uma obsessão com a diferença [...]" (SmulewiczZucker; Thompson, 2015, p. 7).

O liberal da classe média tenta resolver as demandas conflitantes e contraditórias de suas próprias posições privilegiadas dentro do neoliberalismo com a dissonância cognitiva causada por sua professada luta liberal contra a desigualdade. No momento, essa contradição é mais aparente nos esforços de profissionais e administradores dessa classe para negar a relevância do conceito de classe, enquanto continuam a operar dentro das instituições que exploram e excluem a classe 
trabalhadora. A exclusão da classe trabalhadora das instituições do Estado tem consequências não apenas na forma das contínuas desigualdades materiais e políticas da vida da classe trabalhadora, mas também em como entendemos e colocamos em prática o próprio conceito de democracia. Poderíamos escrever outro artigo desconstruindo o conceito de democracia, mas é suficiente aqui indicar a importância de compreender o quão politicamente significativo é esse conceito e a maneira pela qual, como aponta Callinicos (2006), em nosso momento atual, ele é "[...] eficientemente assimilado ao capitalismo liberal" (p. 147). Nosso atual degradado e limitado conceito de democracia distorce tanto a forma como ela é entendida quanto aplicada, especialmente em relação ao poder do Estado de intervir em questões de justiça e igualdade: “[...] sob a hegemonia neoliberal, os poderes de tomada de decisão em áreas-chave da política foram entregues aos mercados financeiros ou transferidos para instituições públicas, como bancos centrais, que não possuem responsabilidade perante os cidadãos ou seus representantes eleitos [...]" (Callinicos, 2006, p. 254).

Esse é, sem dúvida, o cerne do meu argumento em relação à maneira como a educação formal é concebida e oferecida pelo Estado em muitas sociedades. A censura efetiva da cultura da classe trabalhadora dentro das instituições do Estado é obviamente antidemocrática e resultou na dominação dessas instituições pelas atitudes, valores e escolhas táticas de uma classe média sem a experiência de vida da classe trabalhadora. Em uma ampla gama de instituições, pessoas que nelas trabalham não têm conhecimento da pobreza, sofrimento e luta, então é perfeitamente lógico que essas instituições legitimem formas de pensar e ser que tenham como premissa o apagamento das vozes da classe trabalhadora. Como Marx apontou, são as condições sociais que moldam nossa maneira de pensar. Essas condições que moldam nossa maneira de pensar são tanto pessoais quanto institucionais. Nós não podemos, portanto, esperar que aqueles em posições do poder pensem em formas para beneficiar a classe trabalhadora e promover uma transformação da maneira como nós todos vivemos nossas vidas.

Os valores empresariais de subjetividade, competição e individualismo da classe média foram legitimados, tratados como a norma e validados dentro das instituições do Estado como características de uma democracia que funciona. Consequentemente, a possibilidade de considerar as barreiras que esses valores constroem às mudanças políticas e econômicas emancipatórias é minimizada, censurada ou completamente ignorada.

A falta de conhecimento político e social da classe trabalhadora na esfera pública tornou-se mais acentuada nos últimos quarenta anos, dado que a educação está cada vez mais voltada para as ambições de carreira e para a falta de imaginação política da classe média profissional. Ao mesmo tempo, esse estado de coisas é mantido por meio de uma série de sistemas jurídicos e políticos estabelecidos para garantir a hegemonia do sistema neoliberal. 
Mais a Temer do que Esperar

\section{Educação Política Radical}

Uma educação política radical é uma concepção de educação que rejeita a narrativa convencional de transmissão e aquisição de conhecimento e entende a educação como uma reação ao nosso contexto (Biesta, 2006, p. 27) bem como às maneiras pelas quais nossa experiência nesse contexto molda como e o que aprendemos e, consequentemente, condiciona nossa interação com o mundo (O’Neill; Wayne, 2007). Essa abordagem da educação não está envolvida com o acúmulo gradual e inquestionável de fatos, mas é uma estratégia política consciente que analisa a natureza contraditória da totalidade da sociedade. Ela engloba uma abordagem dialética da prática pedagógica que se engaja com a realidade superficial da sociedade como meio de expor os mecanismos subjacentes que produzem essa realidade superficial e, no processo, oferece o potencial para produzir uma compreensão contra-hegemônica do mundo. Um sistema que não é compreendido não pode ser desafiado ou combatido de nenhuma forma significativa, mas apenas experimentado. Uma educação política radical contextualiza essa experiência para que possa ser analisada e interpretada pelas lentes da luta de classes. Essa contextualização é o meio pelo qual se torna possível identificar e se engajar com a diferença cultural e experiencial entre as classes sociais dentro das estruturas do capitalismo. É perceber que o conhecimento existente do mundo quando visto da perspectiva da classe trabalhadora produz não um conhecimento universal, mas uma consciência de como os significados predominantes funcionam separadamente da experiência de ser classe trabalhadora. É importante não subestimar o quão importante pode ser esse reconhecimento de diferença social.

O reconhecimento da diferença social produz a necessidade de pensar diferente: pensar diferente reproduz e confirma o sentido da diferença social. O que é crucial aqui é que o pensamento é diferente [...] sem estar divorciado da realidade social, pensar de forma diferente envolve o subordinado dar sentido à sua subordinação, e não aceitar seu sentido dominante ou criar sentido sem relação com a dominação (Fiske, 1995, p. 58).

Nessa perspectiva da luta pelo significado, é provável que descubramos que as estruturas de que dispomos para construir sentido do mundo signifiquem algo completamente diferente quando vistas pela ótica da luta de classes. Então, podemos iniciar o processo de trazer à tona as inconsistências, contradições e incoerências dentro do modo de produção capitalista e começar a questionar a verdadeira natureza de sua hegemonia supostamente intransponível (Wendling, 2011, p. 5 e 6).

Uma das maneiras pelas quais podemos fazer isso é revisitando e examinando a expansão da oferta de educação para a classe trabalhadora na Inglaterra, primeiro por meio da ampliação do ensino médio na década de 1940 e, posteriormente, da expansão da universidade na década de 1960, que permitiu que alguns membros da classe trabalha- 
dora tivessem acesso a um prolongado processo de escolarização que os removeu de sua classe. Enquanto eles ganhavam acesso aos cânones e às atitudes consagradas das classes média e alta, a educação era projetada e ministrada pela classe média e a aceitação muitas vezes, significava a rejeição de sua classe de origem, sua história, sua cultura e de seu sistema de valores. Os mais brilhantes e melhores da classe trabalhadora foram removidos de seu ambiente para apoiar o discurso de um falso igualitarismo e, no processo, tornaram-se cúmplices da opressão contínua de sua própria classe. Os membros da classe trabalhadora que têm sucesso acadêmico carregam o trauma psicológico de se separarem de sua classe e frequentemente assumem os valores e atitudes da classe dominante à qual chegaram por meio de realizações educacionais. Qualquer tentativa de insistir em sua identidade de classe trabalhadora resulta em ouvir que eles não têm mais o direito de serem reconhecidos como classe trabalhadora (Munt, 2000, p. 9). Isso, é claro, faz todo o sentido se considerarmos o esnobismo inerente a uma cultura de classe média baseada na exclusão da classe trabalhadora (O'Neill 2018, p. 52).

A contínua renovação do capitalismo por aqueles que afirmam estar contribuindo para sua queda é evidente no contínuo agravamento da condição da classe trabalhadora em todo o mundo. Isso ocorre porque há uma falha em compreender que as soluções que oferecem são, elas mesmas, produtos da ordem neoliberal. É por isso que é crucial desconfiarmos de soluções que vêm de dentro das próprias estruturas sociais às quais pretendemos resistir.

Uma educação política radical situa a classe trabalhadora firmemente dentro de sua classe e não considera a educação como um meio de escapar dela. Ela posiciona a classe trabalhadora como distinta das outras classes, a fim de expor o ímpeto universalizante das narrativas hegemônicas. Parte-se da premissa de que a classe trabalhadora tem uma cultura e compartilha experiências históricas e contemporâneas que a diferenciam das demais classes. A ênfase na história a partir da perspectiva da classe trabalhadora, como uma característica de uma educação política radical é crucial, pois como Chris Harman (1998, p. 9) aponta: Se uma classe dominante pode impedir que as pessoas entendam de onde vem a sociedade, ela pode impedir que entendam o desenvolvimento da sociedade e, assim, consolidar seu poder.

As escolas em geral, onde quer que estejam localizadas geograficamente, são esferas da hegemonia da classe média, na maioria das vezes, centradas nas demandas da classe média e na insistência da classe média em um igualitarismo construído sobre a noção de meritocracia, que funciona para mascarar desigualdades estruturalmente enraizadas. É por isso que faz sentido situar a crítica da prática educacional dominante, como indiquei neste ensaio, dentro da estrutura de uma economia global. O neoliberalismo é um sistema político, econômico e ideológico global que alcança todas as áreas de nossas vidas. Nossas vidas são dominadas por corporações multinacionais cuja ganância testemunhou a terceirização de empregos da classe trabalhadora, a privatização de instituições públicas, a falta de responsabilidade demo- 
crática, o esvaziamento das medidas de bem-estar social e a remoção de redes de segurança. O resultado é que as relações sociais e as experiências da classe trabalhadora estão se tornando cada vez mais homogeneizadas, conforme Tyler (2013) indica: "No globalizado século XXI, a polarização econômica atingiu abismos inigualáveis” (Tyler, 2013, p. 5).

Eu diria que essa polarização econômica resultou em uma situação que suscitou duas considerações importantes. Em primeiro lugar, o papel desempenhado pela oferta de uma educação explicitamente despolitizada, que foi projetada para silenciar perspectivas dissidentes e visões alternativas na reprodução e aprofundamento das desigualdades a que Tyler se refere. A segunda consideração é a possibilidade de conceber a classe trabalhadora de diferentes nações não como isolada e distinta uma da outra, mas como potencialmente ligadas. Isso envolve considerar o conceito de globalização especificamente por meio das lentes de classe social. Como Marx e Engels (1967, p. 102) apontaram no manifesto comunista,

Os trabalhadores não têm pátria. As diferenças e os antagonismos nacionais entre os povos estão desaparecendo diariamente, devido ao desenvolvimento da burguesia, à liberdade de comércio, ao mercado mundial, à uniformidade no modo de produção e às condições de vida correspondentes.

O desenvolvimento de uma pedagogia teórica e prática, politicamente comprometida e radical exigirá tempo e um planejamento cuidadoso. Para começar, a questão não é tanto criar um mundo transformado, mas nos orientar na direção de que um mundo transformado se torne uma possibilidade.

Fundamentalmente, envolverá adaptar nossa concepção de educação, tanto quanto possível, à contextualização da vida e das experiências das pessoas da classe trabalhadora. Isso significa posicionar o conceito de classe tanto como experiência pessoal quanto crucialmente como uma força estruturante com poder educativo. Essa abordagem dialética da classe nos permite considerar a importância da experiência baseada na classe social como o ponto de partida para uma educação política radical. A importância de partir do ponto de vista da experiência da classe trabalhadora é dupla. Em primeiro lugar, a experiência da classe trabalhadora é muitas vezes definida por aqueles que não a têm. As indústrias de comunicação, dominadas pela classe média alta, filtram as vidas das pessoas da classe trabalhadora literalmente através das lentes de uma classe média sem experiência de pobreza, desemprego, fome, moradia precária e todas as outras condições da classe trabalhadora. Isso resulta em um fluxo contínuo de estereótipos da vida da classe trabalhadora, que se assemelham muito pouco à vida da classe trabalhadora (O’Neill, 2018, p. 14). A outra razão pela qual essa ênfase na experiência da classe trabalhadora é necessária é porque as experiências materializadas da classe trabalhadora estão em contradição direta com os discursos que pretendem representá-la e com a educação que a ela é imposta. 
$\mathrm{O}$ acesso aos recursos essenciais para a tarefa de comunicar uma oposição organizada, abrangendo versões radicais da realidade social e política, é distribuído de formas extremamente desiguais e dominado por uma classe de elite (Benson, 1978, p. 96). Como vimos, um dos resultados disso é que a classe trabalhadora se tornou cada vez mais excluída da esfera pública, e a cultura da classe trabalhadora tornou-se subordinada à da classe média. Claro, o que é chamado de a deterioração da esfera pública (Boggs, 2000, p. 9) não aconteceu por engano. Em vez disso, demonstra como a tentativa de estabilizar o sistema atual e a continuação da reprodução do neoliberalismo como norma dependem da exclusão e rejeição da cultura da classe trabalhadora: (essas) ideias, valores e experiências da classe dominante são validados no discurso público e são simplesmente considerados como a norma, enquanto os da classe trabalhadora não o são (Cruz, 2021, p. 45).

A natureza contraditória de uma sociedade de classes e o acesso desigual à disseminação do conhecimento e da educação resultam em um antagonismo entre aqueles que são educados e aqueles que recebem uma educação. Como Gramsci (1971) apontou, todas as relações que são hegemônicas devem ser consideradas como relações pedagógicas, uma vez que todas estão envolvidas na luta pela perspectiva que detenha o maior poder de influenciar a educação de outros grupos (Sanbonmatsu, 2004, p. 146). A abordagem de Gramsci (1971) reconhece a natureza de classe não apenas das práticas educacionais, mas de todas as instituições sociais. Isso, por sua vez, chama a atenção para a importância do trabalho em colaboração com grupos subjugados, reconhecendo a particularidade de suas experiências e proporcionando acesso a recursos materiais e ideológicos. Isso significa estimular o questionamento de sua própria visão de mundo do senso comum e da legitimidade da ordem vigente e, assim, gradualmente chegar a uma conceituação dialética da sociedade em que vivem (Allman, 2001, p. 115).

Engels reconhece que é a relação dialética entre o conhecimento e a possibilidade de uma libertação pessoal que levará inevitavelmente a uma sociedade mais justa e igualitária, mas que depende de um envolvimento crítico com as forças em ação. É somente entendendo como essas forças funcionam que seremos capazes de aplicar esse conhecimento para construção de uma sociedade que reconheça a necessidade de todos os membros da sociedade:

\begin{abstract}
As forças ativas da sociedade, enquanto não as conhecemos e reconhecemos, funcionam exatamente como as forças naturais: às cegas, à força e devastadoramente. Mas, quando as conhecemos e compreendemos sua ação, direção e seus efeitos, está em nossas mãos sujeitá-las cada vez mais à nossa vontade e por meio delas, alcançar nossos próprios objetivos [...] quando finalmente dotada deste reconhecimento da natureza real das forças produtivas de hoje, a anarquia social da produção dará lugar a uma regulação social da produção sobre um plano definido, de acordo com as necessidades da comunidade e de cada indivíduo (Engels, 2008, p. 68).
\end{abstract}

Educação \& Realidade, Porto Alegre, v. 46, n. 3, e117080, 2021. 
Mais a Temer do que Esperar

Este questionamento das concepções normativas e princípios universalizados do capitalismo é dependente de uma educação, como Gramsci a concebeu, pela e para a classe trabalhadora de modo que se torne possível "[...] verdadeiramente compreender todas as implicações da noção de classe dominante” (Forgacs, 1988, p. 88). Para Gramsci, assim como para Bourdieu (Callinicos, 2006, p. 82), a disjunção entre as experiências daquele que Gramsci chama de subalterno e o sistema ideológico é aquela que cria contradições em sua relação com o capitalismo. É a consciência da existência dessas contradições que pode iniciar o processo de reconhecimento das instituições do capitalismo e do papel que desempenham na reprodução das relações de classe.

Em minha própria prática, tenho trabalhado com a produção de filmes em que presidiários, ex-presidiários e pessoas que utilizam os bancos de alimentos podem representar suas próprias experiências e narrar suas próprias histórias. Os fundamentos teóricos e práticos da pedagogia radical, que sustenta o projeto Inside Film (O'Neill, 2018), recusam qualquer tentativa de neutralidade. É a recusa de uma abordagem neutra e uniforme para a educação que pode expor as diferenças entre uma educação sancionada pelo estado e outra com potencial libertador (Freire, 1978; hooks, 1994). O projeto Inside Film insiste na dissociação da experiência e do significado da classe trabalhadora do mascaramento ideológico e do universalismo da educação da classe média e, no processo, coloca em foco a especificidade da experiência da classe trabalhadora e do modo de vida da classe trabalhadora. Tanto para Marx (1970, p. 118, 121, 123) quanto para Lukács (1971, p. 262), é por meio do desenvolvimento de poderes cognitivos críticos que se torna possível perceber o capitalismo como um conjunto específico histórico de relações. As narrativas dos estudantes do projeto Inside Film retrataram nos filmes histórias de privação, escárnio, violência e opressão angustiante. Embora não reivindiquemos a experiência como meio de acesso direto à vida das pessoas da classe trabalhadora que participam do projeto, reivindicamos essas narrativas como sistema de conhecimento capaz de expor as inadequações dos modos atuais de conhecer a classe trabalhadora.

Seja qual for a forma que assuma e em que período histórico a estejamos considerando, a educação deve ser reconhecida como uma prática política. Uma educação política radical preocupa-se com a libertação da classe trabalhadora e com a produção de cidadãos criticamente engajados, que trabalharão por uma sociedade mais justa e democrática (Freire, 1978; Giroux, 2014). Uma educação política radical pretende que a educação seja uma prática transformadora ligada à transformação social e pessoal. Freire se referiu a essa educação como um ato cultural e considerou-a como um processo de educar para o desenvolvimento de uma consciência crítica e afirmou que ela tinha o poder de transformar a realidade. Uma educação política radical vincula a educação a questões de agência, legitimação, perspectivas ideológicas e poder. Se considerarmos a educação nesses termos, uma política de redistribuição em busca de uma sociedade mais justa e igualitária não 
pode depender apenas de uma redistribuição da riqueza. Pelo contrário, qualquer mudança duradoura e sustentável depende da redistribuição de ideias (Haylett, 2001, p. 366).

Finalizamos este ensaio com a pergunta que iniciamos: qual seria o impacto de uma educação para a classe trabalhadora pela classe trabalhadora livre do domínio mercadológico empresarial dos grupos educacionais de hoje? Uma prática educacional igualitária nas mãos da classe trabalhadora mudaria o mundo? É uma questão complexa que, como discutimos neste ensaio, engloba o ideológico, o institucional e o poder da imaginação e para a qual não temos resposta... ainda!

Tradução do original em inglês de Vinícius Neves de Cabral

Recebido em 15 de maio de 2021 Aprovado em 20 de julho de 2021

\section{Referências}

ALBORNOZ, Luis (Ed.). Power, Media, Culture: a critical view from the political economy of communication. Houndsmill: Palgrave Macmillan, 2015.

ALLMAN, Paula. Critical Education Against Global Capitalism Karl Marx and Revolutionary Critical Education. Westport: Bergin and Garvey, 2001.

ASHMAN, Sam. The Communist Party Historians Group. In: REES, John (Ed.). Essays On Historical Materialism. London: Bookmarks, 1998.

BENSON, Leslie. Proletarians and Parties. London: Tavistock, 1978.

BIESTA, Gert. Beyond Learning: democratic education for a human future. Paradigm Publishers: Boulder, CO, 2006.

BIRESSI, Anita; NUNN, Heather. Class and Contemporary British Culture. New York: Palgrave Macmillan, 2013.

BOGGS, Carl. The End of Politics: corporate power and the decline of the public sphere. New York: Guilford P, 2000.

BOURDIEU, Pierre. Distinction: a social critique of the judgement of taste. London: Routledge, 1996.

BOWLES, Samuel; GINTIS, Herbert. Schooling in Capitalist America: educational reform and the contradictions of economic life. Chicago: Haymarket Books, 2011.

CALLINICOS, Alex. The Resources of Critique. Cambridge: Cambridge University Press, Polity Press, 2006.

CHOONARA, Joseph. Class and the Classical Marxist Tradition. In: O'NEILL, Deirdre; WAYNE, Mike (Ed). Considering Class: theory, culture and the media in the 21st century. Leiden and Boston: Brill, 2018. P. 13-30.

CONNOLLY, James. Labour, Nationality and Religion. Dublin: 1910. Available at: <https://www.revolutionarycommunist.org/wweb/connolyindexfiles/1910lnr.htm>. Accessed on: 01 Jun. 2021.

CRUZ, Cynthia. The Melancholia of Class: a manifesto for the working class. London: Repeater Books, 2021.

ENGELS, Friedrich. The Condition of the Working Class in England. London: Penguin, 2005.

Educação \& Realidade, Porto Alegre, v. 46, n. 3, e117080, 2021. 
ENGELS, Friedrich. Socialism: utopian and scientific. Chicago: Kerr and Co, 2008.

FISHER, Mark. Capitalist Realism: is there no alternative?. Winchester: O Books, 2012.

FISKE, John. Understanding Popular Culture. London: Routledge, 1995.

FORGACS, David. A Gramsci Reader. London: Lawrence and Wishart, 1988.

FRASER, Nancy; JAEGGI, Rahel. Capitalism: a conversation in critical theory. Cambridge: Polity, 2018.

FREIRE, Paulo. Pedagogy of the Oppressed. Harmondsworth: Penguin, 1978.

FRIEDMAN, Sam; LAURISON, Daniel. The Class Ceiling: why it pays to be privileged. Bristol: Policy Press, 2019.

GIROUX, Henry. Neoliberalism's War on Higher Education. Chicago: Haymarket Books, 2014.

GRAMSCI, Antonio. Selections From the Prison Notebooks. London: Lawrence and Wishart, 1971.

HARMAN, Chris. History, Myth and Marxism. In: REES, John (Ed). Essays On Historical Materialism. London: Bookmarks, 1998.

HARVEY, David. A Brief History of Neo Liberalism. Oxford: Oxford University Press, 2005.

HATCHER, Richard. Class Differentiation in Education: rational choices?. British Journal of Sociology of Education, UK, v. 19, n. 1, p. 5-24, Mar. 1998. Available at: <http://dx.doi.org/10.1080/0142569980190101>. Accessed on: 01 Jun. 2021.

HAYLETT, Chris. Illegitimate Subjects? abject whites, neoliberal modernisation, and middle-class multiculturalism. Environment And Planning D: society and space, v. 19, n. 3, p. 351-370, Jun. 2001. SAGE Publications. Available at: <http://dx.doi.org/10.1068/d237t >. Accessed on: 01 Jun. 2021.

HILL, Dave. Resisting Neo-liberal Global Capitalism and Its Depredations: education for a new democracy. Doing Democracy: Striving for Political Literacy and Social Justice, Counterpoints, v. 322, p. 33-49, 2008.

HILL, Dave. Social Class and Education. In: O'NEILL, Deirdre; WAYNE, Mike (Ed.). Considering Class: theory, culture and the media in the 21st century. Leiden and Boston: Brill, 2018. P. 31-50.

hooks, bell. Teaching to Transgress: education as the practice of freedom. New York: Routledge, 1994

LOCKWOOD, David. The Blackcoated Worker: a study in class consciousness clarendon press. London, 1989.

LOVETT, Tom; CLARKE, Chris; KILMURRAY, Avila. Adult Education and Community Action. London: Croom Helm, 1983.

LUKÁCS, György. History and Class Consciousness: studies in marxist dialectics. London: Merlin Press, 1971.

MARX, Karl. 'Theses On Feurbach'. In: MARX, Karl; ENGELS, Friedrich. The German Ideology. London: Lawrence and Wishart, 1970.

MARX, Karl. The $18^{\text {th }}$ Brumaire of Louis Bonaparte. New York: International Publishers, 1977.

MARX, Karl; ENGELS, Friedrich. The Communist Manifesto. Harmondsworth: Penguin Books, 1967. 
MCGUIGAN, Jim. Cool Capitalism. London: Pluto, 2010.

MCLAUGHLIN, Kenneth. Stigma, and Its Discontents. Newcastle: Cambridge Scholars Publishing, 2021.

MUNT, Sally (Ed.). Cultural Studies and the Working Class. London: Cassell, 2000.

O'NEILL, Deirdre. Film as a Radical Pedagogic Tool. New York; London: Routledge, 2018.

O'NEILL, Deirdre; WAYNE, Mike. Film as a Radical Pedagogic Tool. In: Film International. 29 Sep./Oct. 2007.

PARENTI, Michael. The Culture Struggle. New York: Seven Stories Press, 2006.

REAY, Diane. Finding or Losing Yourself? working-class relationships to education. Journal Of Education Policy, UK, v. 16, n. 4, p. 333-346, Jul. 2001. Available at: <http://dx.doi.org/10.1080/02680930110054335>. Accessed on: 01 jun. 2021.

REAY, Diane. Miseducation: inequality, education and the working classes. Bristol: Monthly Review Policy Press, 2017.

SANBONMATSU, John. The Postmodern Prince. New York: Monthly Review Press, 2004.

SAPON-SHEVIN, Mara. Inclusive Education, High Stakes Testing and Capitalist Schooling. Monthly Review, New York, v. 63, n. 03, Jul./Aug. 2011.

SAVAGE, Mike. Class Analysis and Social Transformation. Buckingham: Open University Press, 2000.

SCHWARTZ, Joseph. Being Postmodern While Late Modernity Burned: on the apolitical nature of contemporary self-defined 'radical' political theory. In: SMULEWICZ-ZUCKER, Gregory; THOMPSON, Michael. Radical Intellectuals and the Subversion of Progressive Politics: the betrayal of politics. New York: Palgrave, 2015.

SEABROOK, Jeremy. Globalising the Working Class. Third World Network, Aug. 1999. Available at: <https://twn.my/title/1938-cn.htm>. Accessed on: 12 mar. 2021.

STEAD, Peter. A Paradoxical Turning Point: 1959 to 1960. In: ROWBOTHAM, Sheila; BENYON, Huw (Ed.). Looking at Class: film television and the working class in britain. London: Rivers Oram Press, 2001.

THOBURN, Nicholas. Patterns of Production. Theory, Culture \& Society, SAGE Publications, v. 24, n. 3, p. 79-94, May 2007. Available at: <http://dx.doi. org/10.1177/0263276407075959>. Accessed on: 01 jun. 2021.

TODD, Selina. Snakes and Ladders: the great british social mobility myth. London: Chatto and Windus, 2021.

TYLER, Imogen. Revolting Subjects: social abjection and resistance in neoliberal Britain. London: Zed Books, 2013.

WENDLING, Amy. Karl Marx on Technology and Alienation. London: Palgrave Macmillan, 2011.

WINLOW, Simon. Beyond Measure: on the marketization of british universities, and the domestication of academic criminology (forthcoming in critical criminology). 2021. 
Deirdre O'Neill é professora da University of Hertfordshire (UK) e cineasta da classe trabalhadora. Ela é a editora principal do Journal of Class and Culture e co-coordenadora do Inside Film Project< $<$ http://www.insidefilm.org $>$. Ela codirigiu (com Mike Wayne) três filmes: Listen to Venezuela <http://listentovenezuela.info>, Condition of the Working Class <http://www.conditionoftheworkingclass.info $>\mathrm{e}$, seu filme mais recente, The Acting Class sobre a falta de atores da classe trabalhadora $<$ https://theactingclass.info/>. ORCID: https://orcid.org/0000-0003-4332-2117

E-mail: d.oneill3@herts.ac.uk

Editora-responsável: Carla Vasques

Este é um artigo de acesso aberto distribuído sob os termos de uma Licença Creative Commons Atribuição 4.0 Internacional. Disponível em: <http:// creativecommons.org/licenses/by/4.0>. 